\title{
Complete genome sequence of Denitrovibrio acetiphilus type strain $\left(\mathbf{N} 2460^{\top}\right)$
}

\author{
Hajnalka Kiss ${ }^{1,2}$, Elke Lang ${ }^{3}$, Alla Lapidus ${ }^{1}$, Alex Copeland ${ }^{1}$, Matt Nolan ${ }^{1}$, Tijana Glavina Del \\ Rio", Feng Chen ${ }^{1}$, Susan Lucas ${ }^{1}$, Hope Tice ${ }^{1}$, Jan-Fang Cheng ${ }^{1}$, Cliff Han ${ }^{1,2}$, Lynne \\ Goodwin ${ }^{1,2}$, Sam Pitluck ${ }^{1}$, Konstantinos Liolios ${ }^{1}$, Amrita Pati ${ }^{1}$, Natalia Ivanova ${ }^{1}$, \\ Konstantinos Mavromatis ${ }^{1}$, Amy Chen ${ }^{4}$, Krishna Palaniappan ${ }^{4}$, Miriam Land ${ }^{1,5}$, Loren \\ Hauser $^{1,5}$, Yun-Juan Chang ${ }^{1,5}$, Cynthia D. Jeffries ${ }^{1,5}$, John C. Detter ${ }^{1,5}$, Thomas Brettin ${ }^{1,5}$, \\ Stefan Spring ${ }^{3}$, Manfred Rohde ${ }^{6}$, Markus Göker ${ }^{3}$, Tanja Woyke ${ }^{1}$, James Bristow ${ }^{1}$, Jonathan A. \\ Eisen $^{1,7}$, Victor Markowitz ${ }^{4}$, Philip Hugenholtz ${ }^{1}$, Nikos C. Kyrpides ${ }^{1}$, Hans-Peter Klenk ${ }^{3 *}$ \\ ${ }^{1}$ DOE Joint Genome Institute, Walnut Creek, California, USA \\ ${ }^{2}$ Los Alamos National Laboratory, Bioscience Division, Los Alamos, New Mexico, USA \\ ${ }^{3}$ DSMZ - German Collection of Microorganisms and Cell Cultures GmbH, Braunschweig, \\ Germany \\ ${ }^{4}$ Biological Data Management and Technology Center, Lawrence Berkeley National \\ Laboratory, Berkeley, California, USA \\ ${ }^{5}$ Oak Ridge National Laboratory, Oak Ridge, Tennessee, USA \\ ${ }^{6} \mathrm{HZI}$ - Helmholtz Centre for Infection Research, Braunschweig, Germany \\ ${ }^{7}$ University of California Davis Genome Center, Davis, California, USA
}

*Corresponding author: Hans-Peter Klenk

Keywords: dissimilatory nitrate-reducer, mesophile, free-living, marine, obligately anaerobic, motile, Deferribacteraceae, Deferribacteres, GEBA

Denitrovibrio acetiphilus Myhr and Torsvik 2000 is the type species of the genus Denitrovi-
brio in the bacterial family Deferribacteraceae. It is of phylogenetic interest because there are
only six genera described in the family Deferribacteraceae. D. acetiphilus was isolated as a
representative of a population reducing nitrate to ammonia in a laboratory column simulating
the conditions in off-shore oil recovery fields. When nitrate was added to this column unde-
sirable hydrogen sulfide production was stopped because the sulfate reducing populations
were superseded by these nitrate reducing bacteria. Here we describe the features of this ma-
rine, mesophilic, obligately anaerobic organism respiring by nitrate reduction, together with
the complete genome sequence, and annotation. This is the second complete genome se-
quence of the order Deferribacterales and the class Deferribacteres, which is the sole class in
the phylum Deferribacteres. The 3,222,077 bp genome with its 3,034 protein-coding and 51
RNA genes is part of the Genomic Encyclopedia of Bacteria and Archaea project.

\section{Introduction}

Strain N2460 ${ }^{\mathrm{T}}$ (= DSM 12809) is the type strain of the species Denitrovibrio acetiphilus, which is the type species of the genus Denitrovibrio [1]. When this genus was described in 2000, it was the second validly published genus name in the phylum Deferribacteres Garrity and Holt 2001. Based on an extended analysis of $16 \mathrm{~S}$ rRNA gene sequences, the phylum Deferribacteres was recently described as comprising the genera Deferribacter, Denitrovibrio, Flexistipes, Geovibrio and Mucispirillum [2]. However, the species Calditerrivibrio ni- troreducens unequivocally also belongs to this phylum (Figure 1) [9].

In offshore oil extraction, reservoir souring by sulfate-reducing bacteria is of great economic concern. Seawater which naturally contains sulfates is injected into the reservoirs to enhance oil recovery. This sulfate load initiates the growth of sulfate-reducing bacteria producing $\mathrm{H}_{2} \mathrm{~S}$ as the end product of sulfate respiration. Besides being toxic and corrosive, $\mathrm{H}_{2} \mathrm{~S}$ increases the sulfur content of the oil and may contribute to the plugging of the 
reservoir $[10,11]$. Strain $\mathrm{N} 2460^{\mathrm{T}}$ was isolated from a laboratory model column simulating marine anoxic mineral oil reservoir conditions. The aim of these model experiments was to evaluate the feasibility to stop bacterial sulfate reduction by the addition of nitrate. The idea was to shift (redox) conditions in such a way that nitrate reducing populations supersede the sulfatereducing populations. In the field, expensive biocides had often to be added to the injection water to prevent the negative effects of souring. For that reason, the application of nitrate or nitrite as a substitute showed great economic promise in oil exploitation [10]. There are several other older patents concerning the addition of nitrate or nitrite to aqueous systems with the aim to avoid biological $\mathrm{H}_{2} \mathrm{~S}$ production and the associated odor nuisance ("Patent 4,681,687 cites the use of sodium nitrite to control SRB and $\mathrm{H}_{2} \mathrm{~S}$ in flue gas desulfurization sludge"; US patent 5,405,531 of 1995 cites the injection of nitrate, nitrite and molybdate to inhibit sulfate reducing bacteria and hence prevent sulfide production). The application in order to manipulate the microbial communities in oil reservoirs has also been termed "Bio-Competitive Exclusion technology" [12].

In the laboratory model column from which strain $\mathrm{N} 2460^{\mathrm{T}}$ was isolated, bacterial sulfate reduction with crude oil as carbon and energy source was established first. Subsequently, the column was inoculated with an enrichment of nitrate-reducing bacteria deriving from ballast water, and $0.5 \mathrm{mM}$ sodium nitrate was added to the circulating sea- water [1]. Strain $\mathrm{N} 2460^{\mathrm{T}}$ was isolated after further enrichment in marine medium with acetate and nitrate as the electron donor and acceptor, respectively. As appraised by microscopic observation, the main population after nitrate application to the model column consisted of Denitrovibrio acetiphilus-like bacteria.

There are no reports of other strains of $D$. acetiphilus having been isolated. The species of the closest related genera, Geovibrio and Deferribacter, share 16S rRNA sequence identities of 85.3$85.9 \%$ and $84.2-85.7 \%$, respectively [13]. The sequence similarity with phylotypes in environmental screenings and metagenomic libraries were all below $90 \%$, except one single hit in the Wallaby gut metagenome (ADGC01007328, unpublished, 94\%), indicating an extremely poor representation of closely related strains in the habitats analyzed (status March 2010). Here we present a summary classification and a set of features for $D$. acetiphilus strain $\mathrm{N} 2460^{\mathrm{T}}$, together with the description of the complete genome sequencing and annotation.

\section{Classification and features}

Figure 1 shows the phylogenetic neighborhood of D. acetiphilus strain $\mathrm{N}^{2} 460^{\mathrm{T}}$ in a $16 \mathrm{~S}$ rRNA based tree. The two 16S rRNA gene sequences in the genome differ by one nucleotide from each other, and differ by up to one nucleotide from the previously published $16 \mathrm{~S}$ rRNA sequence (AF146526) generated from DSM 12809.

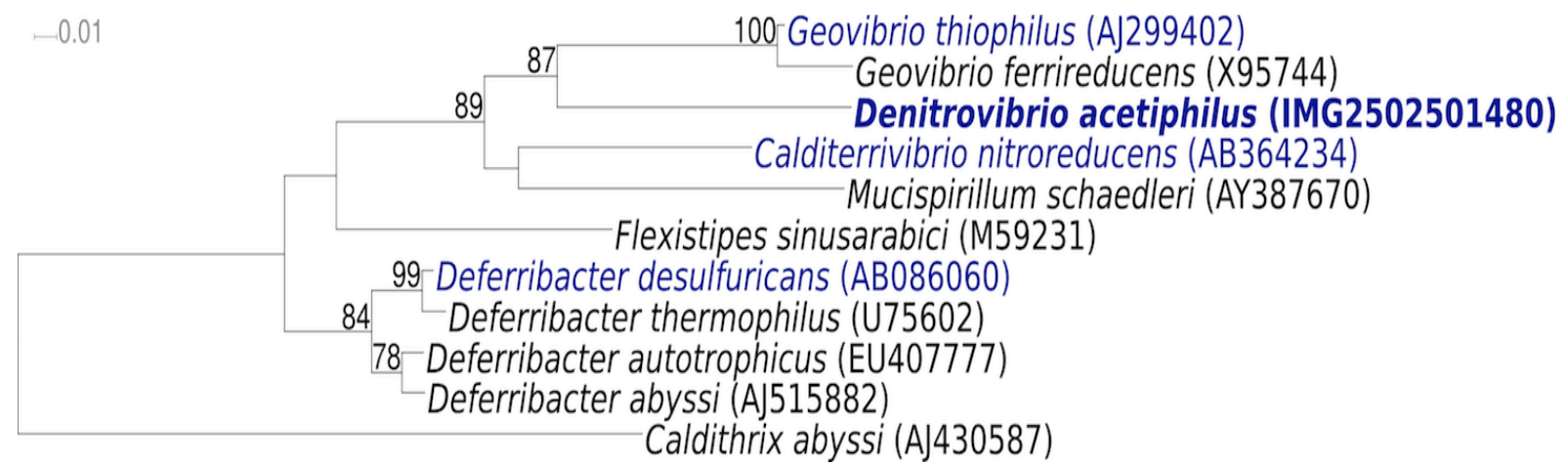

Figure 1. Phylogenetic tree highlighting the position of $D$. acetiphilus strain $\mathrm{N} 2460^{\top}$ relative to the other species within the phylum Deferribacteres. The tree was inferred from 1,460 aligned characters [3,4] of the $16 \mathrm{~S}$ rRNA sequence under the maximum likelihood criterion [5] and rooted with Caldithrix abyssi ('Unclassified Deferribacterales'). The branches are scaled in terms of the expected number of substitutions per site. Numbers above branches are support values from 800 bootstrap replicates [6] if larger than 60\%. Strains with a genome sequencing project registered in GOLD [7] are printed in blue; published genomes in bold [8]. 
Cells of strain $\mathrm{N} 2460^{\mathrm{T}}$ are vibroid bacteria measuring 1.7-2.0 x 0.5-0.7 $\mu \mathrm{m}$ (Figure 2 and Table 1), multiplying by budding and showing rapid corkscrew movement. The strain is obligately anaerobic, and its growth is inhibited by oxygen and by anoxic non-reduced conditions. The bacterium is very versatile regarding the salt concentration of its environment as it grows in salt concentrations of $0-6 \% \mathrm{NaCl}(\mathrm{w} / \mathrm{v})$. It grows at temperatures between 4 and $40^{\circ} \mathrm{C}$ with an optimum at $35-37^{\circ} \mathrm{C}$ and at $\mathrm{pH}$ 6.5-8.6. The shortest doubling time at $35^{\circ} \mathrm{C}$ is about $8 \mathrm{~h}$. Vitamins are required for growth [1].

Under the enrichment conditions, the cells gain energy by nitrate dissimilation with ammonia as the end product. In addition, the bacteria are able to grow on fumarate by fermentation [1]. The respiratory metabolism is restricted to a very limited substrate spectrum as the bacteria do not grow with benzoic acid, short chain alcohols, alkanes, carbohydrates, hydrogen or fatty acids other than acetate or pyruvate as the electron donor. However, this specialization on acetate needs not limit the spread of the organism in nature for acetate is a common fermentation product in almost any anoxic environment. As activity of 2-oxoglutarate dehydrogenase was present but carbon-monoxide dehydrogenase activity - the key-enzyme of the acetyl-CoA pathway -was absent in the cells, it was concluded that metabolization of acetate occurs via citric acid cycle [1].

As found for most strictly anaerobic nitrate reducing bacteria such as Wolinella succinogenes [23], D. acetiphilus reduces nitrate to the end product am- monia when growing by anaerobic respiration. This pathway should be delineated from the respiratory denitrification of facultatively anaerobic organisms which reduce nitrate to nitrous oxide or dinitrogen. Several obligately anaerobic nitrate-to-ammonium reducers gain energy only from the first reduction step from nitrate to nitrite (nitrate reductases). Some of these organisms may use this 6-electron transfer reduction as an electron sink for the regeneration of oxidized coenzymes during fermentation of carbohydrates, catalyzed by nitrite dependent reductase. In other anaerobes, such as W. succinogenes, Desulfovibrio desulfuricans or D. gigas, however, the reduction of nitrite to ammonia is also coupled to the electron transport phosphorylation [1]. Whether or not strain N2460 $\mathrm{T}$ is capable of gaining energy from the reduction of nitrite to ammonia is an unresolved question yet.

Another feature of the dissimilatory metabolism of strain $\mathrm{N}^{2460^{\mathrm{T}}}$ still awaits clarification: are these bacteria able to perform iron reduction as are several of its close phylogenetic relatives such as Deferribacter thermophilus or Geovibrio ferrireducens? Attempts to test for this ability in the lab failed because the addition of ferric pyrophosphate raised the redox potential to such an extend that growth of $D$. acetiphilus, which is sensitive to non-reduced conditions, was inhibited [1]. No other electron acceptor than nitrate (optimum concentration $8 \mathrm{mM}$ ) was found to support growth of strain N2460 ${ }^{\mathrm{T}}$ so far [1]. In this property, D. acetiphilus resembles another member of the Deferribacteres, $C$. nitroreducens which, however, is much more versatile regarding the electron donors than D. acetiphilus [9].

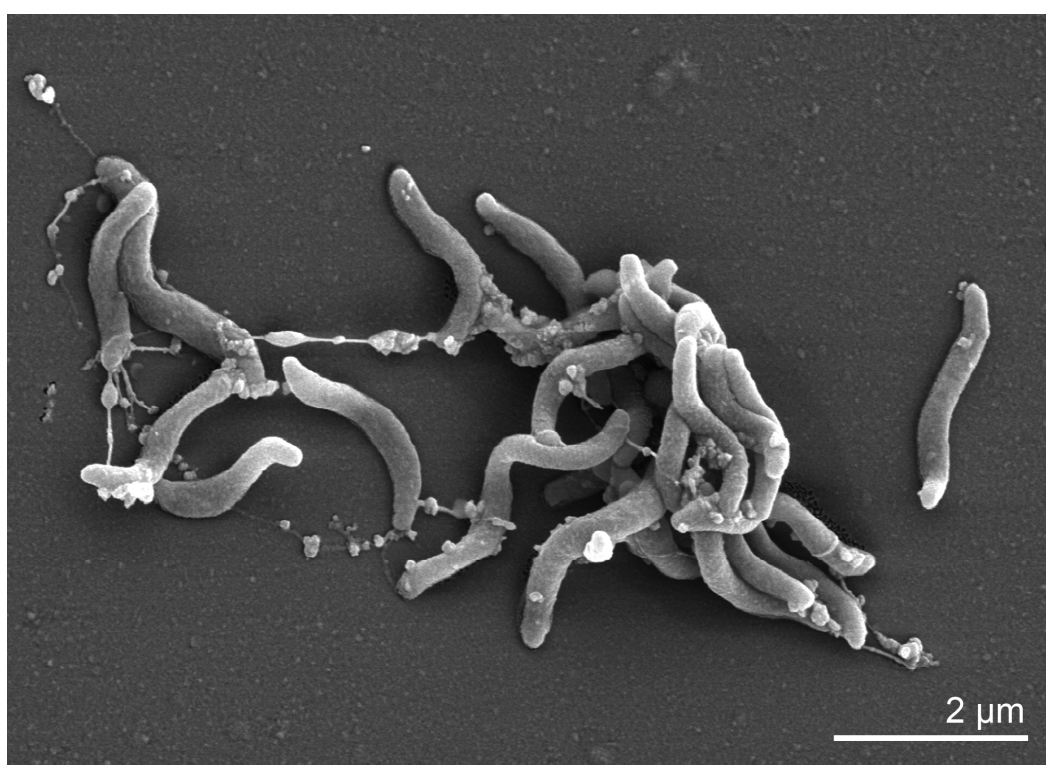

Figure 2. Scanning electron micrograph of D. acetiphilus strain N2460 


\begin{tabular}{|c|c|c|c|}
\hline MIGS ID & Property & Term & Evidence code \\
\hline & \multirow{8}{*}{ Classification } & Domain Bacteria & TAS [15] \\
\hline & & Phylum Deferribacteres & TAS [16-18] \\
\hline & & Class Deferribacteres & TAS $[16,19]$ \\
\hline & & Order Deferribacterales & TAS $[16,19]$ \\
\hline & & Family Deferribacteraceae & TAS $[16,20]$ \\
\hline & & Genus Denitrovibrio & TAS [1] \\
\hline & & Species Denitrovibrio acetiphilus & TAS [1] \\
\hline & & Type strain N2460 & TAS [1] \\
\hline & Gram stain & negative & TAS [1] \\
\hline & Cell shape & vibroid & TAS [1] \\
\hline & Motility & motile & TAS [1] \\
\hline & Sporulation & spores not observed & TAS [1] \\
\hline & Temperature range & mesophile, $4-40^{\circ} \mathrm{C}$ & TAS [1] \\
\hline & Optimum temperature & $35-37^{\circ} \mathrm{C}$ & TAS [1] \\
\hline \multirow{4}{*}{ MIGS-22 } & Salinity & halophilic, grows at $0-6 \%(\mathrm{w} / \mathrm{v}) \mathrm{NaCl}$, & TAS [1] \\
\hline & Oxygen requirement & obligately anaerobic, nitrate reducer & TAS [1] \\
\hline & Carbon source & $\begin{array}{l}\text { acetate or pyruvate (dissimilation), } \\
\text { fumarate (fermentation) }\end{array}$ & TAS [1] \\
\hline & Energy source & chemoorganotroph & TAS [1] \\
\hline MIGS-6 & Habitat & marine & TAS [1] \\
\hline MIGS-15 & Biotic relationship & free living & NAS \\
\hline \multirow[t]{3}{*}{ MIGS-14 } & Pathogenicity & none & NAS \\
\hline & Biosafety level & 1 & TAS [21] \\
\hline & Isolation & oil reservoir, model column & TAS [1] \\
\hline MIGS-4 & Geographic location & Bergen (Norway) & TAS [1] \\
\hline MIGS-5 & Sample collection time & about or before 2000 & TAS [1] \\
\hline MIGS-4.1 & Latitude & 60.388 & NAS \\
\hline MIGS-4.2 & Longitude & 5.331 & NAS \\
\hline MIGS-4.3 & Depth & unknown & \\
\hline MIGS-4.4 & Altitude & unknown & \\
\hline
\end{tabular}

Evidence codes - IDA: Inferred from Direct Assay (first time in publication); TAS: Traceable Author Statement (i.e., a direct report exists in the literature); NAS: Non-traceable Author Statement (i.e., not directly observed for the living, isolated sample, but based on a generally accepted property for the species, or anecdotal evidence). These evidence codes are from of the Gene Ontology project [22]. If the evidence code is IDA, then the property was directly observed by one of the authors or an expert mentioned in the acknowledgements.

\section{Chemotaxonomy}

Phospholipid fatty acids are the major fraction of the polar lipids contained in bacterial cells. The principal constituents of the phospholipids in $\mathrm{N} 2460^{\mathrm{T}}$ are unsaturated hexadecenoic acid and octadecenoic acid; other compounds are other straight chain saturated and unsaturated fatty acids [1]. The species Flexistipes sinusarabici, which also belongs to the phylum Deferribacteres, contains saturated hexadecanoic acid and octadecanoic acid as major compounds as well as iso- and anteiso-branched fatty acids in its polar lipids [1]. The predominant compounds in whole cell lipids of $C$. nitroreducens are isotetradecanoic and anteiso-pentadecanoic acid [9].
Thus, the yet described composition of the fatty acids within the Deferribacteres shows a wide variability. The presence of respiratory lipoquinones have not been reported, but it may be predicted that they should be present, since this is a feature of all members of the phylum examined to date.

\section{Genome sequencing and annotation Genome project history}

This organism was selected for sequencing on the basis of its phylogenetic position [24], and is part of the Genomic Encyclopedia of Bacteria and Archaea project [25]. The genome project is deposited in the 
Genomes OnLine Database [7] and the complete genome sequence in GenBank. Sequencing, finishing and annotation were performed by the DOE Joint
Genome Institute (JGI). A summary of the project information is shown in Table 2.

Table 2. Genome sequencing project information

\begin{tabular}{|c|c|c|}
\hline MIGS ID & Property & Term \\
\hline MIGS-31 & Finishing quality & Finished \\
\hline MIGS-28 & Libraries used & $\begin{array}{l}\text { Three genomic libraries: Sanger } 8 \mathrm{~kb} \text {, } \\
\text { pMCL200 and fosmid libraries; one } 454 \\
\text { pyrosequence standard library }\end{array}$ \\
\hline MIGS-29 & Sequencing platforms & ABI3730, 454 GS FLX \\
\hline MIGS-31.2 & Sequencing coverage & $7.8 \times$ Sanger; $27.5 \times$ pyrosequence \\
\hline MIGS-30 & Assemblers & Newbler version 1.1.02.15, phrap \\
\hline \multirow[t]{6}{*}{ MIGS-32 } & Gene calling method & Prodigal 1.4, GenePRIMP \\
\hline & Genbank ID & СР001968 \\
\hline & Genbank Date of Release & March 11, 2010 \\
\hline & GOLD ID & Gc01249 \\
\hline & NCBI project ID & 29431 \\
\hline & Database: IMG-GEBA & 2502422320 \\
\hline \multirow[t]{2}{*}{ MIGS-13 } & Source material identifier & DSM 12809 \\
\hline & Project relevance & Tree of Life, GEBA \\
\hline
\end{tabular}

\section{Growth conditions and DNA isolation}

D. acetiphilus strain $\mathrm{N} 2460^{\mathrm{T}}$, DSM 12809, was grown anaerobically in DSMZ medium 881 (Denitrovibrio medium) [26] at $30^{\circ} \mathrm{C}$. DNA was isolated from 1-1.5 g of cell paste using Qiagen Genomic 500 DNA Kit (Qiagen, Hilden, Germany) with lysis modification st/L according to Wu et al. [25].

\section{Genome sequencing and assembly}

The genome was sequenced using a combination of Sanger and 454 sequencing platforms. All general aspects of library construction and sequencing can be found at the IGI website. Pyrosequencing reads were assembled using the Newbler assembler version 1.1.02.15 (Roche). Large Newbler contigs were broken into 3,494 overlapping fragments of $1,000 \mathrm{bp}$ and entered into assembly as pseudo-reads. The sequences were assigned quality scores based on Newbler consensus q-scores with modifications to account for overlap redundancy and adjust inflated qscores. A hybrid 454/Sanger assembly was made using the parallel phrap assembler (High Performance Software, LLC). Possible misassemblies were corrected with Dupfinisher or transposon bombing of bridging clones [27]. A total of 1,442
Sanger finishing reads were produced to close gaps, to resolve repetitive regions, and to raise the quality of the finished sequence. The final assembly contains 29,464 Sanger reads and 450,080 pyro-sequencing reads. Together, the combination of the Sanger and 454 sequencing platforms provided $35.3 \times$ coverage of the genome. The error rate of the completed genome sequence is less than 1 in 100,000 .

\section{Genome annotation}

Genes were identified using Prodigal [28] as part of the Oak Ridge National Laboratory genome annotation pipeline, followed by a round of manual curation using the IGI GenePRIMP pipeline [29]. The predicted CDSs were translated and used to search the National Center for Biotechnology Information (NCBI) nonredundant database, UniProt, TIGR-Fam, Pfam, PRIAM, KEGG, COG, and InterPro databases. Additional gene prediction analysis and functional annotation was performed within the Integrated Microbial Genomes - Expert Review (IMG-ER) platform [30]. 


\section{Genome properties}

The genome is $3,222,077$ bp long and comprises one main circular chromosome with an overall $\mathrm{G}+\mathrm{C}$ content of $42.5 \%$ (Table 3 and Figure 3 ) which is in very good accord with the figure given earlier after HPLC-determination (42.6\%) [1]. Of the 3,085 genes predicted, 3,034 were proteincoding genes, and 51 RNAs; 70 pseudogenes were also identified. The majority of the protein-coding genes (74.4\%) were assigned a putative function while those remaining were annotated as hypothetical proteins. The distribution of genes into COGs functional categories is presented in Table 4 .

\section{Insights in the genome}

Anaerobic dissimilatory nitrate reduction can be carried out by denitrifying bacteria which are facultative anaerobes releasing the end product dinitrogen or by strict anaerobes which reduce ni- trate to the end product ammonium. The first step, the reduction from nitrate to nitrite occurs in both metabolic types. The respective enzymes are encoded by gene families nar (nitrate reductase) and nap (periplasmic nitrate reductase) [31]. The operons encoding the nitrite reduction in denitrifying bacteria are named nir, nor and nos whereas the respective genes in the nitrate ammonifying bacteria are $n r f$ [23]. The annotation of the N2460 ${ }^{\mathrm{T}}$ genome identified three genes encoding subunits of respiratory nitrate reductase (EC 1.7.99.4). These were identified as resembling known narG, narH and narL genes, thus they most probably encode for the alpha-, beta- and gamma-subunit of nitrate reductase. The automated search also detected Dacet_0792 resembling in part the gene $n f r B$ encoding for a compound of the multi-unit cytochrome $\mathrm{c}$ nitrite reductase.

Table 3. Genome Statistics

\begin{tabular}{lrr}
\hline Attribute & Value & \% of Total \\
\hline Genome size (bp) & $3,222,077$ & $100.00 \%$ \\
DNA coding region (bp) & $3,006,341$ & $93.30 \%$ \\
DNA G+C content (bp) & $1,370,563$ & $42.54 \%$ \\
Number of replicons & 1 & \\
Extrachromosomal elements & 0 & \\
Total genes & 3,085 & $100.00 \%$ \\
RNA genes & 51 & $1.65 \%$ \\
rRNA operons & 2 & \\
Protein-coding genes & 3,034 & $98.35 \%$ \\
Pseudo genes & 70 & $2.27 \%$ \\
Genes with function prediction & 2,296 & $74.42 \%$ \\
Genes in paralog clusters & 469 & $15.20 \%$ \\
Genes assigned to COGs & 2,287 & $74.13 \%$ \\
Genes assigned Pfam domains & 2,407 & $78.02 \%$ \\
Genes with signal peptides & 620 & $20.10 \%$ \\
Genes with transmembrane helices & 755 & $24.47 \%$ \\
CRISPR repeats & 0 & \\
\hline
\end{tabular}




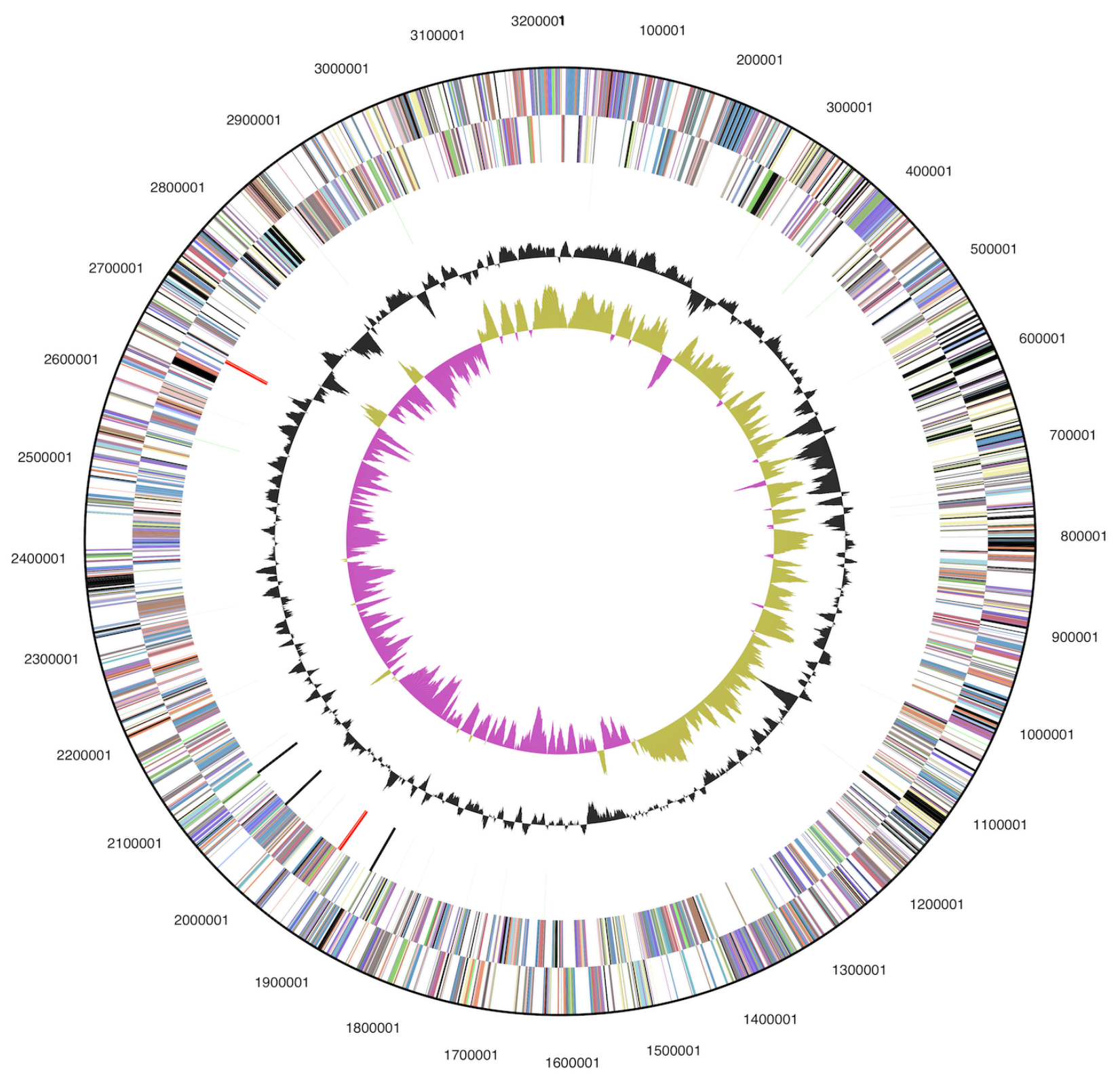

Figure 3. Graphical circular map of the chromosome. From outside to the center: Genes on forward strand (color by COG categories), Genes on reverse strand (color by COG categories), RNA genes (tRNAs green, rRNAs red, other RNAs black), GC content, GC skew.

Table 4. Number of genes associated with the general COG functional categories

\begin{tabular}{lrrl}
\hline Code & value & \%age & Description \\
\hline J & 145 & 5.8 & Translation, ribosomal structure and biogenesis \\
A & 0 & 0.0 & RNA processing and modification \\
K & 147 & 5.8 & Transcription \\
L & 180 & 7.1 & Replication, recombination and repair \\
B & 1 & 0.0 & Chromatin structure and dynamics \\
D & 23 & 0.9 & Cell cycle control, mitosis and meiosis \\
Y & 0 & 0.0 & Nuclear structure \\
\hline
\end{tabular}




\begin{tabular}{lrrl}
\multicolumn{3}{l}{ Table 4 (cont.) } & Number of genes associated with the general COG functional categories \\
\hline Code & value & \%age & Description \\
\hline V & 46 & 1.8 & Defense mechanisms \\
T & 257 & 10.2 & Signal transduction mechanisms \\
M & 155 & 6.2 & Cell wall/membrane/envelope biogenesis \\
N & 103 & 4.1 & Cell motility \\
Z & 0 & 0.0 & Cytoskeleton \\
W & 0 & 0.0 & Extracellular structures \\
U & 74 & 2.9 & Intracellular trafficking and secretion \\
O & 89 & 3.5 & Posttranslational modification, protein turnover, chaperones \\
C & 220 & 8.7 & Energy production and conversion \\
G & 92 & 3.7 & Carbohydrate transport and metabolism \\
E & 182 & 7.2 & Amino acid transport and metabolism \\
F & 62 & 2.5 & Nucleotide transport and metabolism \\
H & 126 & 5.0 & Coenzyme transport and metabolism \\
I & 47 & 1.9 & Lipid transport and metabolism \\
P & 140 & 5.6 & Inorganic ion transport and metabolism \\
Q & 20 & 0.8 & Secondary metabolites biosynthesis, transport and catabolism \\
R & 263 & 10.4 & General function prediction only \\
S & 148 & 5.9 & Function unknown \\
- & 798 & 25.9 & Not in COGs \\
\hline & & &
\end{tabular}

\section{Acknowledgements}

We would like to gratefully acknowledge the help of Markus Kopitz for growing the D. acetiphilus cells, and Susanne Schneider for DNA extraction and quality analysis (both at DSMZ). This work was performed under the auspices of the US Department of Energy's Office of Science, Biological and Environmental Research Program, and by the University of California, Lawrence Berkeley National Laboratory under contract No. DE-

\section{References}

1. Myhr S, Torsvik T. Denitrovibrio acetiphilus, a novel genus and species of dissimilatory nitratereducing bacterium isolated from an oil reservoir model column. Int J Syst Microbiol 2000; 50:16111619.

2. Jumas-Bilak E, Roudière L, Marchandin H. Description of "Synergistetes" phyl. nov. and emended description of the phylum "Deferribacteres" and of the familiy Syntrophomonadaceae, phylum "Firmicutes". Int J Syst Microbiol 2009; 59:1028-1035. doi:10.1099/ijs.0.006718-0

3. Lee C, Grasso C, Sharlow MF. Multiple sequence alignment using partial order graphs. Bioinformatics 2002; 18:452-464. $\quad$ PubMed doi:10.1093/bioinformatics/18.3.452
AC02-05CH11231, Lawrence Livermore National Laboratory under Contract No. DE-AC52-07NA27344, Los Alamos National Laboratory under contract No. DEAC02-06NA25396, and UT-Battelle and Oak Ridge National Laboratory under contract DE-AC05-000R22725, as well as German Research Foundation (DFG) INST 599/1-2.

4. Castresana J. Selection of conserved blocks from multiple alignments for their use in phylogenetic analysis. Mol Biol Evol 2000; 17:540-552. PubMed

5. Stamatakis A, Hoover P, Rougemont J. A Rapid Bootstrap Algorithm for the RAxML Web Servers. Syst Biol 2008; 57:758-771. doi:10.1080/10635150802429642

6. Pattengale ND, Alipour M, Bininda-Emonds ORP, Moret BME, Stamatakis A. How Many Bootstrap Replicates Are Necessary? Lect Notes Comput Sci 2009; 5541:184-200. doi:10.1007/978-3-642$\underline{02008-7 \_13}$

7. Liolios K, Chen IM, Mavromatis K, Tavernarakis N, Hugenholtz P, Markowitz VM, Kyrpides NC. The 
Genomes On Line Database (GOLD) in 2009: status of genomic and metagenomic projects and their associated metadata. Nucleic Acids Res 2010; 38:D346-D354. PubMed doi:10.1093/nar/gkp848

8. Takaki $Y$, Shimamura $S$, Nakagawa S, Fukuhara $Y$, Horikawa H, Ankai A, Harada T, Hosoyama A, Oguchi A, Fukui S, et al. Bacterial lifestyle in deepsea hydrothermal vent chimney revealed by the genome sequence of the thermophilic bacterium Deferribacter desulfuricans SSM1. DNA Res 2010

9. lino T, Nakagawa T, Mori K, Harayama S, Suzuki K. Calditerrivibrio nitroreducens gen. nov., sp. nov., a thermophilic, nitrate-reducing bacterium isolated from a terrestrial hot spring in Japan. Int J Syst Evol Microbiol 2008; 58:1675-1679. PubMed doi:10.1099/ijs.0.65714-0

10. Myhr S, Lillebø BL, Sunde E, Beeder J, Torsvik T. Inhibition of microbial $\mathrm{H}_{2} \mathrm{~S}$ production in an oil reservoir model column by nitrate injection. Appl Microbiol Biotechnol 2002; 58:400-408. PubMed doi:10.1007/s00253-001-0881-8

11. Reinsel MA, Sears JT, Stewart PS, Mclnerney MJ. Control of microbial souring by nitrate, nitrite or glutaraldehyde injection in a sandstone column. J Ind Microbiol Biotechnol 1996; 17:128-136.

12. Anchiliya A. New nitrate-based treatments - a novel approach to control hydrogen sulfide in reservoir and to increase oil recovery. SPE europec/EAGE Annual Conference and Exhibition, 1215 June 2006, Vienna Austria. doi 10.2118/100337-MS.

13. Chun J, Lee JH, Jung Y, Kim M, Kim S, Kim BK, Lim YW. EzTaxon: a web-based tool for the identification of prokaryotes based on $16 \mathrm{~S}$ ribosomal RNA gene sequences. Int J Syst Evol Microbiol 2007; 57:2259-2261. PubMed doi:10.1099/ijs.0.64915-0

14. Field D, Garrity G, Gray T, Morrison N, Selengut J, Sterk P, Tatusova T, Thompson N, Allen MJ, Anguiuoli SV, et al. Towards a richer description of our complete collection of genomes and metagenomes: the "Minimum Information about a Genome Sequence" (MIGS) specification. Nat Biotechnol 2008; 26:541-547. PubMed doi:10.1038/nbt1360

15. Woese CR, Kandler O, Wheelis ML. Towards a natural system of organisms: proposal for the domains Archaea, Bacteria, and Eucarya. Proc Natl Acad Sci USA 1990; 87:4576-4579. doi:10.1073/pnas.87.12.4576

16. List Editor. Validation of publication of new names and new combinations previously effectively published outside the IJSEM. Validation List no. 85. Int
J Syst Evol Microbiol 2002; 52:685-690. PubMed doi:10.1099/ijs.0.02358-0

17. Garrity GM, Holt JG. Phylum BIX. Deferribacteres phyl. nov. In: Garrity GM, Boone DR, Castenholtz RW (eds), Bergey's Manual of Systematic Bacteriology, Second Edition, Volume 2, Part C, Springer, New York, 2005, p. 465.

18. Jumas-Bilak E, Roudière L, Marchandin H. Description of 'Synergistetes' phyl. nov. and emended description of the phylum 'Deferribacteres' and the family Syntrophomonadaceae, phyl. 'Firmicutes'. Int J Syst Evol Microbiol 2009; 59:1028-1035. PubMed doi:10.1099/ijs.0.006718-0

19. Huber H, Stetter KO. Class I. Deferribacteres class. nov. In: Garrity GM, Boone DR, Castenholz RW (eds), Bergey's Manual of Systematic Bacteriology, Second Edition, Volume 1, Springer, New York, 2001, p. 465.

20. Huber H, Stetter KO. Family I. Deferribacteraceae fam. nov. In: Garrity GM, Boone DR, Castenholz RW (eds), Bergey's Manual of Systematic Bacteriology, Second Edition, Volume 1, Springer, New York, 2001, p. 465-466.

21. Classification of. Bacteria and Archaea in risk groups. www.baua.de TRBA 466.

22. Ashburner M, Ball CA, Blake JA, Botstein D, Butler $\mathrm{H}$, Cherry JM, Davis AP, Dolinski K, Dwight SS, Eppig JT, et al. Gene ontology: tool for the unification of biology. Nat Genet 2000; 25:25-29. PubMed doi:10.1038/75556

23. Simon J. Enzymology and bioenergetics of respiratory nitrite ammonification. FEMS Microbiol Rev 2002; 26:285-309. PubMed doi:10.1111/j.15746976.2002.tb00616.x

24. Klenk HP, Göker M. En route to a genome-based taxonomy of Archaea and Bacteria? Syst Appl

Microbiol 2010; 33:175-182. PubMed doi:10.1016/j.syapm.2010.03.003

25. Wu D, Hugenholtz P, Mavromatis K, Pukall R, Dalin E, Ivanova N, Kunin V, Goodwin L, Wu M, Tindall BJ. A phylogeny-driven genomic encyclopedia of Bacteria and Archaea. Nature 2009; 462:10561060. PubMed doi:10.1038/nature08656

26. List of growth media used at DSMZ: http://www.dsmz.de/microorganisms/media_list.ph p

27. Sims D, Brettin T, Detter J, Han C, Lapidus A, Copeland A, Glavina Del Rio T, Nolan M, Chen F, Lucas $\mathrm{S}$, et al. Complete genome sequence of $\mathrm{Ky}$ tococcus sedentarius type strain $\left(541^{\top}\right)$. Stand Genomic Sci 2009; 1:12-20. doi:10.4056/sigs.761 
28. Hyatt $\mathrm{D}$, Chen $\mathrm{GL}$, Locascio PF, Land ML, Larimer FW, Hauser LJ. Prodigal Prokaryotic Dynamic Programming Genefinding Algorithm. BMC Bioinformatics 2010; 11:119. PubMed doi:10.1186/14712105-11-119

29. Pati A, Ivanova N, Mikhailova N, Ovchinikova G, Hooper SD, Lykidis A, Kyrpides NC. GenePRIMP: A Gene Prediction Improvement Pipeline for microbial genomes. Nat Methods 2010; 7:455-457. doi:10.1038/nmeth.1457. PubMed
30. Markowitz VM, Ivanova NN, Chen IMA, Chu K, Kyrpides NC. IMG ER: a system for microbial genome annotation expert review and curation. Bioinformatics 2009; 25:2271-2278. $\quad$ PubMed doi:10.1093/bioinformatics/btp393

31. Smith CJ, Nedwell DB, Dong LF, Osborn AM. Diversity and abundance of nitrate reductase genes (narG and napA), nitrite reductase genes ( $n i r S$ and $n r f A)$, and their transcripts in estuarine sediments. Appl Environ Microbiol 2007; 73:3612-3622. PubMed doi:10.1128/AEM.02894-06 